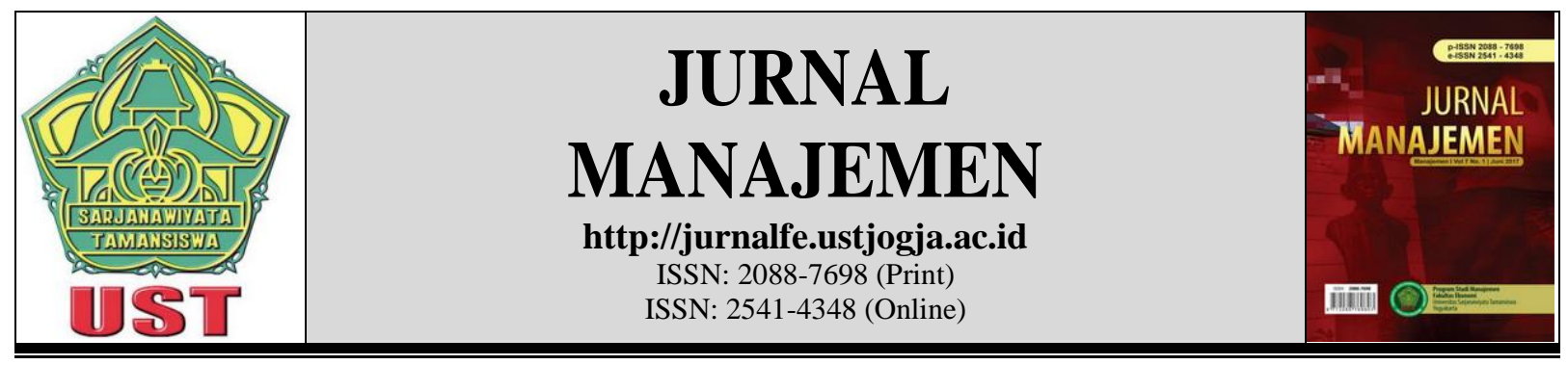

\title{
PENGARUH PERSEPSI MAHASISWA TENTANG VARIASI PEMBELAJARAN MATA KULIAH BANK DAN LEMBAGA KEUANGAN LAINNYA
}

\author{
Sri Hermuningsih ${ }^{1}$ \\ Kristi Wardani ${ }^{2}$ \\ Kusuma Chandra Kirana ${ }^{3}$
}
1,3Magister Manajemen, Fakultas Ekonomi Universitas Sarjanawiyata
Tamansiswa Yogyakarta
${ }^{2}$ PGSD, FKIP Universitas Sarjanawiyata Tamansiswa Yogyakarta

\section{Korespondensi: hermun_feust@yahoo.co.id}

\begin{tabular}{ll}
\hline Informasi Naskah & \multicolumn{1}{c}{ Abstrak } \\
\hline Diterima: & The purpose of this study was to assess the students' perceptions \\
19 November 2017 & about learning subjects of Banks and Other Financial Institutions \\
Revisi: & with a contextual approach. \\
2 Desember 2017 & The sample of the study are 50 student of Economic Faculty \\
Terbit: & Universitas Sarjanawiyata Tamansiswa, which cover subjects UST \\
6 Desember 2017 & Banks and Other Financial Institutions. The method of analysis \\
\hline Kata Kunci: & with behavioral approach system usage information Technology \\
Perception, contextual & Acceptance Model (TAM). \\
approach, Banks and & The results show that Student perceptions in the course study of \\
Other Financial & Bank and other financial institutions with contextual approach \\
Institutions & categories are very high by 26\% high category of 62\% and \\
& moderate category of 12\%. \\
\hline
\end{tabular}

\section{PENDAHULUAN}

Bank dan Lembaga Keuangan Lainnya merupakan salah satu mata kuliah wajib pada Program Studi manajemen. Mata kuliah ini menekankan pada pemahaman konsep, penalaran, pengambilan keputusan yang berkaitan dengan proses pelayanan dalam bidang industri jasa. Konten yang sebagian besar mengandung unsur perhitungan, cenderung menjadi momok bagi sebagian besar mahasiswa. Masih banyak mahasiswa yang gagal dalam evaluasi mata kuliah Bank Dan Lembaga Keuangan Lainnya. 
Banyak hal yang diduga menjadi kesulitan dan kegagalan dalam pembelajaran tersebut. Hal ini dapat berasal dari beberapa faktor, seperti fasilitas, kurikulum, sumber belajar, metode penyampaian/pembelajaran oleh dosen. Pembelajaran masih terlalu didominasi peran dosen (teacher centered), peserta didik lebih banyak ditempatkan sebagai objek. Pelaksanaan ujian telah dievaluasi, dan memberikan kesimpulan bahwa beberapa hal menjadi penyebab kegagalan mahasiswa, di antaranya adalah : metode yang konvensional (ceramah) yang sangat membosankan, kurangnya minat dalam proses pembelajaran karena kurang memahami materi yang diberikan, rendahnya motivasi untuk memahami dan terlibat dalam setiap aktifitas pembelajaran.

Untuk dapat mencapai tujuan pembelajaran, dosen harus mengetahui banyak hal, yang berkaitan dengan karakteristik mahasiswa, sehingga mampu menggunakan beragam metode. Penggunaan metode yang beragam ini akan mampu menarik minat mahasiswa untuk memahami materi yang disampaikan. Pendekatan pembelajaran haruslah dirubah dari teacher centered kepada student centered. Abu dan Nur (2001) pengajaran kontekstual memungkinkan siswa menguatkan, memperluas, dan menerapkan pengetahuan dan keterampilan akademik mereka dalam berbagai macam tatanan dalam sekolah dan di luar sekolah agar siswa dapat memecahkan masalah-masalah dunia nyata atau masalah-masalah yang disimulasikan.

Tujuan penelitian ini adalah mengkaji tentang pengaruh persepsi mahasiswa tentang variasi pembelajaran mata kuliah Bank dan Lembaga Keuangan Lainnya. Hasilnya nanti diharapkan akan dapat merekomendasikan pendekatan pembelajaran yang sesuai.

\section{KAJIAN PUSTAKA DAN HIPOTESIS Pembelajaran Kontekstual}

Menurut UU Nomor 20 tahun 2003 tentang Sisdiknas, pembelajaran adalah proses interaksi peserta didik dengan pendidik dan sumber belajar pada suatu lingkungan belajar. Jadi pembelajaran merupakan proses interaksi peserta didik dengan pendidik dan sumber belajar pada suatu lingkungan belajar. Pembelajaran merupakan bantuan yang diberikan pendidik agar dapat terjadi proses pemerolehan ilmu dan pengetahuan. Jadi dapat dikatakan teori belajar merupakan upaya untuk mendeskripsikan bagaimana manusia belajar, sehingga membantu kita semua memahami proses inhern yang kompleks dari belajar.

Sebenarnya, dalam belajar siswa atau mahasiswa tidak berada di awan tetapi berada di bumi yang selalu menyatu dengan tempat belajar, waktu, situasi, dan suasana alam dan masyrakatnya. Untuk itu, salah satu pendekatan yang dianggap tepat untuk mengembangkan pembelajaran adalah pendekatan kontekstual. Pembelajaran kontekstual adalah konsepsi pembelajaran yang membantu guru atau dosen menghubungkan mata pelajaran dengan situasi dunia nyata dan pengetahuan yang memotivasi siswa agar menghubungkan pengetahuan dan terapannya dengan kehidupan sehari-hari sebagai anggota keluarga dan masyarakat (Ardiana, 2001). Pembelajaran kontekstual muncul sebagai reaksi terhadap teori behavioristik yang telah mendominasi pendidikan selama ini. Menurut Ahmadi dan Nur (2001), pengajaran kontekstual memungkinkan siswa menguatkan, memperluas, dan menerapan pengetahuan dan keterampilan akademik mereka dalam berbagai macam tatanan dalam sekolah dan di luar sekolah agar siswa dapat memecahkan masalah-masalah dunia nyata.

Blanchard (2001) mengembangkan strategi pembelajaran dengan pendekatan kontekstual dengan: (1) menekankan pemecahan masalah; (2) menyadari kebutuhan pengajaran dan pembelajaran yang terjadi dalam berbagai kontekstual; (3) mengajar siswa memonitor dan mengarahkan pembelajaran mereka sendiri sehingga menjadi siswa mandiri; (4) mengaitkan pengajaran pada konteks kehidupan siswa yang berbeda-beda; (5) mendorong siswa untuk 
belajar dari sesama teman dan belajar bersama, dan (6) menerapkan penilaian autentik. Dalam pendekatan kontekstual ini ada tujuh elemen penting meliputi:

a. Penemuan (Inquiry)

Penemuan merupakan bagian inti kegiatan pembelajaran berbasis kontekstual. Siswa tidak menerima pengetahuan dan keterampilan hanya dari mengingat seperangkat fakta-fakta saja, tetapi berasal dari pengalaman menemukan sendiri. Guru harus selalu merancang pembelajaran yang bersumber dari penemuan. Pembelajaran dirancang dengan menarik dan menantang, sehingga siswa dapat menemukan sendiri tanpa harus dari buku. Pada siklus penemuan meliputi; a) observasi; b) bertanya; c) mengajukan dugaan; d) pengumpulan data; dan e) penyimpulan.

b. Pertanyaan

Biasanya, pengetahuan dan keterampilan yang dimiliki seseorang berawal dari sebuah pertanyaan. Pertanyaan berguna untuk mendorong, membimbing, dan menilai kemampuan siswa. Bagi siswa, pertanyaan berguna untuk menggali informasi, mengecek informasi yang didapatnya, mengarahkan perhatian, dan memastikan penemuan yang dilakukannya.

c. Konstruktivistik

Siswa perlu dibiasakan memecahkan masalah, menemukan sesuatu yang berguna bagi dirinya, dan bergelut dengan ide-idenya. Melalui seperti itu, siswa dapat mengonstruksikan gejala-gejala dengan pemikirannya sendiri. Konstruktivistik merupakan landasan berpikir metode kontekstual, yaitu bahwa pengetahuan dibangun sedikit demi sedikit yang hasilnya diperluas melalui konteks yang terbatas dan tidak seketika. Manusia harus mengkonstruksikan pengetahuan dan memberi makna melalui pengalaman tidak melalui ingatan dan hafalan saja.

d. Pemodelan

Pemodelan adalah pemberian model agar siswa dapat belajar dari model tersebut. Guru dapat memberikan model karya tulis, model paragraf atau kalimat dan seterusnya. Dari model tersebut, siswa dapat mengidentifikasi selanjutnya membuat seperti model yang ditunjukkan. Dalam kontekstual, guru bukanlah model satu-satunya. Model dapat diambil dari mana saja.

e. Komunitas Belajar

Kerja sama dengan orang lain dapat memberikan pengalaman belajar bagi siswa. Siswa dapat mengembangkan pengalaman belajarnya setelah berdiskusi dengan temannya. Masyarakat belajar menyarankan bahwa hasil pembelajaran diperoleh dari kerja sama dengan orang lain, siswa dapat saling bertukar pendapat dan dilaksanakan dalam kelompok belajar dengan anggota-anggota heterogen.

f. Penilaian Otentik

Dalam kontekstual, perkembangan belajar siswa dapat diketahui melalui pengumpulan data dari aktivitas belajar siswa secara langsung di kelas. Penilaian tidak dilakukan di belakang meja atau di rumah saja tetapi juga di saat siswa aktif belajar di kelas.

g. Refleksi

Refleksi merupakan respon terhadap pengalaman yang telah dilakukan, aktivitas yang baru dijalani, dan pengetahuan yang baru saja diterima. Dengan merefleksikan sesuatu, siswa merasa memperoleh sesuatu yang berguna bari dirinya tentang apa yang baru dipelajari. Refleksi tersebut dapat dilakukan per bagian, di akhir jam pelajaran, di akhir bab/tema, atau dalam kesempatan apapun. Realisasi refleksi dapat berupa pernyataan spontan siswa tentang 
apa yang diperolehnya hari itu seperti catatan di lembar kertas, diskusi, kata kunci dan lainnya.

\section{METODE PENELITIAN}

\section{Desain Penelitian}

Populasi penelitian mahasiswa Fakultas Ekonomi Universitas Sarjanawiyata Tamansiswa Program Studi Manajemen semester empat. Sampelnya sebanyak 100 mahasiswa yang mengambil mata kuliah Bank Dan Lembaga Keuangan Lainnya. Pengambilan sampel dengan metode purposive sampling. Analisis data dilakukan secara deskriptif kualitatif.

\section{Definisi Operasional}

\section{Persepsi}

Persepsi dalam penelitian ini sesuai dengan apa yang dikemukakan oleh Kotler (2012) bahwa persepsi adalah sebagai proses bagaimana seseorang menyeleksi, mengatur dan menginterpretasikan masukan-masukan informasi untuk menciptakan gambaran keseluruhan yang berarti

Persepsi yaitu proses di mana individu-individu mengorganisasikan dan menafsirkan kesan indera mereka agar memberi makna kepada lingkungan mereka. Persepsi mahasiswa terhadap pembelajaran manajemen produksi dengan indikator dan sub indikator sebagai berikut :

1. Pebelajar (pihak yang menjadi fokus) yang perlu diketahui dengan sub indikator karakteristik mereka, kemampuan awal dan pra syarat

2. Instruktur adalah yang mengajar dengan sub indikator pembimbing, dinamisator, fasilitator, dan motivator

3. Tujuan pembelajaran (umum dan khusus ) adalah penjabaran kompetensi yang akan dikuasai oleh pebelajar dengan sub indikator kompetensi

4. Strategi Pembelajaran, dapat dilakukan secara makro (dalam kurun satu tahun) atau mikro (dalam kurun satu kegiatan belajar mengajar) dengan sub indikator adalah kejelasan, variasi, orientasi tugas, keterlibatan siswa dalam belajar

5. Bahan ajar, adalah format materi yang akan diberikan kepada pebelajar dengan sub indikator Ketersediaan bahan, kesesuaian, mudah dipahami

\section{HASIL DAN PEMBAHASAN}

Pada penelitian ini diawali dengan melaksanakan kegiatan pembelajaran dengan langkah pendekatan kontekstual. Adapun langkah pendekatan tersebut meliputi :

\section{Tabel 1 Langkah pendekatan kontekstual dalam mata kuliah Bank dan Lembaga Keuangan Lainnya}

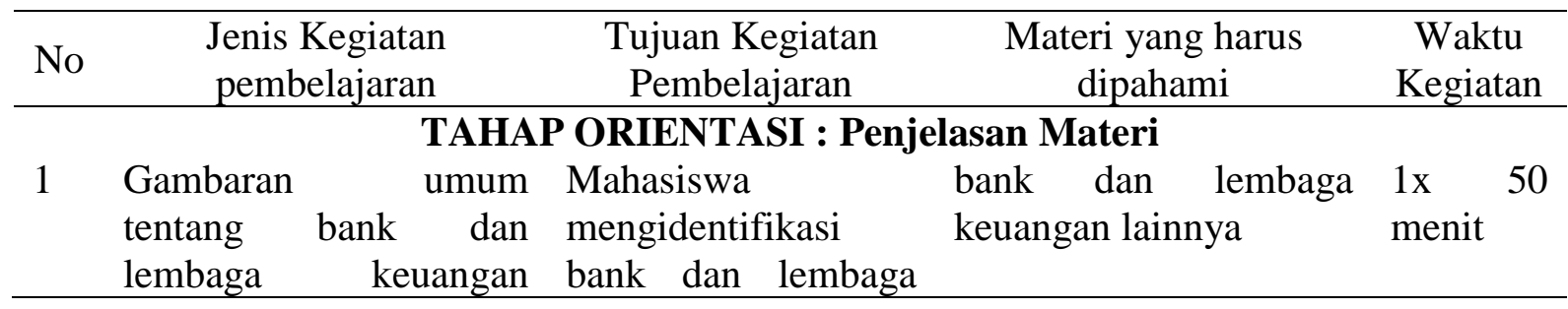




\begin{tabular}{|c|c|c|c|}
\hline & lainnya & $\begin{array}{l}\text { keuangan lainnya } \\
\text { TAHAPAN LATIHAN }\end{array}$ & \\
\hline 2 & $\begin{array}{l}\text { Penjelasan tentang } \\
\text { pendekatan kontekstual } \\
\text { dalam matakuliah bank } \\
\text { dan lembaga keuangan } \\
\text { lainnya } \\
\text { TAHA }\end{array}$ & $\begin{array}{l}\text { a. Mahasiswa bank dan lembaga } \\
\text { melakukan } \\
\text { orientasi dan } \\
\text { langkah } \\
\text { pendekatan } \\
\text { kontekstual. } \\
\text { b. Mahasiswa lainnya } \\
\text { mendiskusikan } \\
\text { bank dan lembaga } \\
\text { keuangan lainnya } \\
\text { EVALUASI: Penyebaran angket }\end{array}$ & $\begin{array}{l}1 \mathrm{x} \\
\text { menit }\end{array}$ \\
\hline
\end{tabular}

Penelitian ini berupaya untuk mengetahui pengaruh persepsi mahasiswa tentang Pembelajaran Mata Kuliah Bank Dan Lembaga Keuangan Lainnya Dengan Pendekatan Kontekstual. Dalam penelitian ini akan disajikan hasil analisis deskriptif persepsi. Identifikasi kecenderungan tinggi rendahnya skor persepsi mahasiswa tentang pembelajaran mata kuliah Bank dan Lembaga keuangan lainya diteteapkan berdasarkan kriteria ideal. Kecenderungan persepsi mahasiswa tentang Pembelajaran Mata Kuliah Bank Dan Lembaga Keuangan Lainnya Dengan Pendekatan Kontekstual dapat dilihat pada gambar berikut ini:

Gambar 1.

Persepsi mahasiswa tentang Pembelajaran Mata Kuliah Bank Dan

Lembaga Keuangan Lainnya Dengan Pendekatan Kontekstual

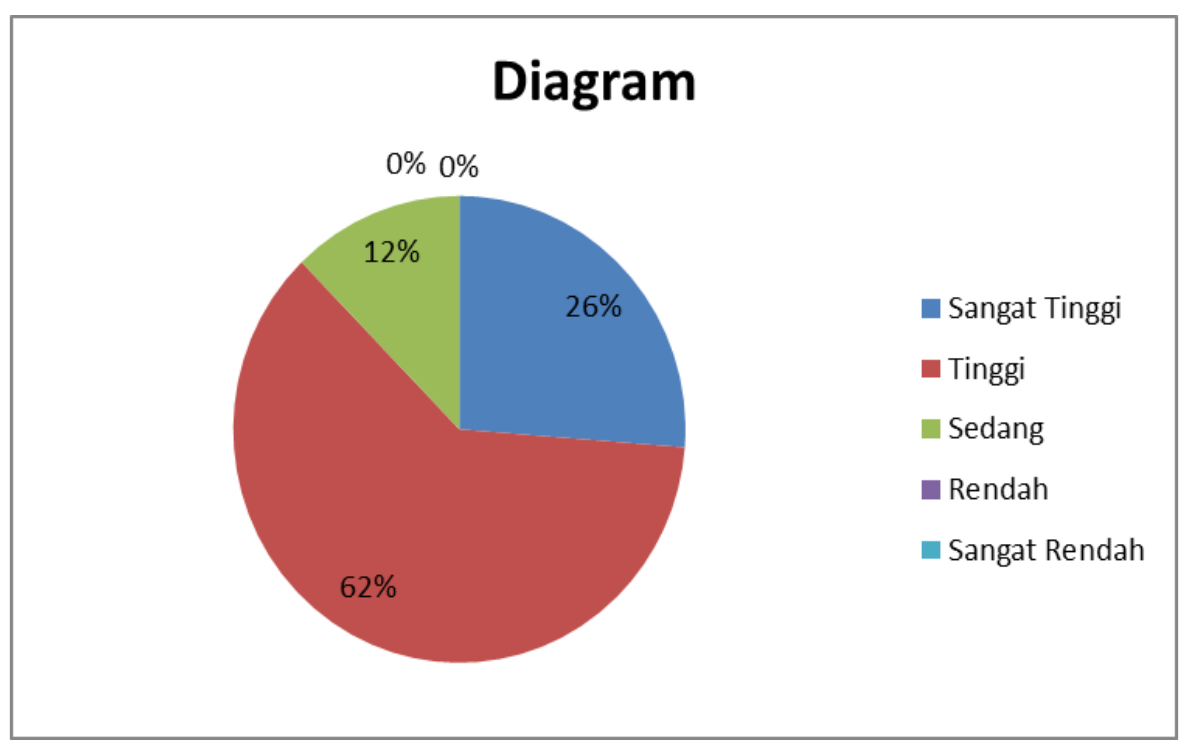

Gambar 1 menunjukkan bahwa persepsi mahasiswa dalam pembelajaran mata kuliah Bank dan lembaga keuangan lainnya dengan pendekatan kontekstual sebagai berikut: kategori sangat tinggi sebesar $26 \%$ kategori tinggi sebesar $62 \%$ dan kategori sedang sebesar $12 \%$. Hal ini menunjukkan bahwa persepsi mahasiswa tentang pembelajaran mata kuliah Bank dan 
lembaga keuangan lainnya dengan pendekatan kontekstual tergolong tinggi, karena didominasi mahasiswa yang memiliki persepsi baik sebesar $62 \%$. Adapun Rata-rata skor adalah 93,3 berada pada kategori tinggi.

Apabila melihat kecenderungan di atas, dapat dikatakan bahwa persepsi mahasiswa tentang pembelajaran mata kuliah Bank dan lembaga keuangan lainnya dengan pendekatan kontekstual tergolong cukup baik. Hal ini menunjukkan bahwa pelaksanaan pembelajaran mata kuliah Bank dan lembaga keuangan lainnya dengan pendekatan kontekstual di Fakultas Ekonomi Universitas Sarjanawiyata Tamansiswa telah berjalan dengan tinggi yang ditunjukkan persepsi yang didominasi oleh persepsi yang tinggi. Dengan pelaksanaan pembelajaran mata kuliah Bank dan lembaga keuangan lainnya dengan pendekatan kontekstual yang sudah dipersepsi tinggi oleh mahasiswa seharusnya diikuti meningkatnya hasil atau prestasi belajar mahasiswa fakultas Ekonomi.

\section{PENUTUP}

Persepsi mahasiswa dalam pembelajaran matakuliah Bank dan lembaga keuangan lainnya dengan pendekatan kontekstual kategori sangat tinggi sebesar $26 \%$ kategori tinggi sebesar $62 \%$ dan kategori sedang sebesar $12 \%$. Hal ini menunjukkan bahwa persepsi mahasiswa tentang pembelajaran mata kuliah Bank dan lembaga keuangan lainnya dengan pendekatan kontekstual tergolong tinggi, karena didominasi mahasiswa yang memiliki persepsi baik sebesar $62 \%$. Rata-rata skor adalah 93,3 berada pada kategori tinggi.

\section{Saran}

Penelitian ini baru sebatas pada subjek mahasiswa, sehingga penelitian untuk mengetahui persepsi dan pemahaman dosen pengampu mata kuliah bank dan lembaga keuangan lainnya sehingga lingkup penelitian dapat meluas di perguruan tinggi lain

\section{REFERENSI}

Ahmadi, Abu dan Uhbiyati, Nur, 2001. Ilmu Pendidikan Jakarta. PT Rineka Cipta

Ardiana, Leo Idra, 2001. Pembelajaran Kontekstual. Makalah.

Blanchard, A, 2001. Contextual Teaching and learning: Primary learning Theories. (On Line) tersedia di http;//www.Besteducationalservice.com//contextual//htm. (18 Februari 2002).

Djamarah, Syaiful Bahri dan Aswan Zain. 2002. Strategi Belajar Mengajar. Jakarta: Rineka Cipta

Hermuningsih,, Sri, Kristi Wardani. 2016. Persepsi Mahasiswa tentang Pembelajaran Mata Kuliah Bank Dan Lembaga Keuangan Lainnya

Jonhson, Elaine B. 2009. Contextual Teaching and Learning. (Terjemahan Ibnu Setiawan, Cetakan VII). Bandung: Mizan Learning Center.

Kotler Philip, dan Gary Amstrong, 201. Principles Of Marketing, Global Edition, 14 Edition, Pearson Education

Rahayu, Sri. Penerapan Model Kontekstual dalam Pembelajaran Menulis Pada Siswa Kelas XII SMKN 1 Denpasar. E- Jurnal Program Pasca Sarjana Pendidikan Ganesha PBSI (Volume 2 Tahun 2013

Undang-Undang Nomor 20 tahun 2003 Tentang Sisdiknas \& Peraturan Pemerintah Republik Inodonesia Tahun 2010 Tentang Penyelenggaraan Pendidikan serta Wajin Belajar. Bandung: Cita Umabara 